\title{
Behavior and flagellar currents in coronate polyps (Scyphozoa) and comparisons with semaeostome polyps
}

\author{
D. M. Chapman \\ Department of Anatomy, Dalhousie University; \\ Halifax, Nova Scotia, Canada
}

\begin{abstract}
KURZFASSUNG: Verhalten und Geißelströme bei Polypen der Coronate (Scyphozoa) und Vergleiche mit Polypen der Semaeostomeae. Bei Stephanoscyphus, dem Polypen der Ordnung Coronatae, existiert neben der typischen die atypische, blumenähnliche Form S. racemosus, während alle Polypen der Ordnung Semaeostomeae gleichartig sind. Die verschiedenen Körperregionen der drei Polypenformen wurden auf ihr Verhalten nach der Reizung mit einem Glasstab und auf das Vorhandensein von Geißelströmen untersucht. Hinsichtlich des Verhaltens ist die wichtigste Beobachtung, daß bei dem Polypen der Semaeostomeae die starke Reizung eines Tentakels die anderen Körperregionen nicht beeinflußst, während bei der typischen Form des Coronatenpolypen der gleiche Versuch die Retraktion des Polypen und die Verkürzung aller Tentakel zur Folge hat. Der Polyp der Coronatae besitzt daher eine kompliziertere neurologische Struktur. Bei dem Polypen der Semaeostomeae existieren an den Tentakeln kräftige Geißelströme, während bei den Coronatenpolypen solche fehlen. Bei letzteren wurde die Defäkation nach der Fütterung beobachtet; sie ist verbunden mit einer Hyperextension und einer seitlichen Verbreiterung des Kopfendes, dessen Rand nach außen umgeschlagen wird, ferner mit einer Umkehr der Richtung des Geißelschlages im Coelenteron und möglicherweise mit einer schnellen Kontraktion als Endphase. Die Defäkation wurde beim Polypen der Semaeostomeae nicht beobachtet, doch ist es möglich, bei ihm die Schlagumkehr der Geißeln im Coelenteron hervorzurufen.
\end{abstract}

\section{INTRODUCTION}

Prior to WERNER's $(1966,1967,1970)$ recent interest in the polyps of the Order Coronatae (Scyphozoa), these polyps have not been much studied and those who have turned their attention to this group have recorded little concerning the behavior.

Until polyp can be linked with medusa, the coronate polypoid stage is said to belong to the genus Stephanoscyphus. Coronate polyps will be the subject of a monograph by Dr. B. WERNER in whose laboratory I had the privilege of observing numerous species he has under cultivation.

Other than remarking that the polyp retreats into its periderm tube when disturbed, the older workers had little to say on the activities of these animals. WERNER (1966) described the tucking in of the tentacles and rolling in of the crown during retraction.

As to flagella and flagellar currents, Schulze (1877) quotes EtMer (p. 796) as 
saying the tentacles have flagella and KOMAI (1935) states the only region with many flagella is on the filaments. SoUTHWARD (1955) points out that cnidarians have flagella and not cilia so that one strictly should talk of flagellar currents. He points out that common usage does allows the term "ciliary current"; however, I have chosen to avoid the terms "cilia" and "ciliary" currents.

There are two main types of coronate polyps: the colonial atypical Stephanoscyphus racemosus described by Komal (1935) and the usual sort which may be solitary or colonial.

The results of this study are compared to observations made on another scyphozoan polyp type, namely the polyps (scyphistoma) of the Order Semaeostomeae, especially Aurelia aurita.

Figures 2-6 are accurate illustrations taken from life of the polyps discussed in this communication and were provided through the kindness of Dr. B. WERNER.

\section{MATERIALS AND METHODS}

Several species of Stephanoscyphus are examined:

(a) Solitary species: (1) Stephanoscyphus sp. 1 collected in 1964 in the Indian Ocean. (2) Stephanoscypbus sp. 6 collected in 1967 at two locations near the Moroccan and Portuguese coasts (Fig. 2). (3) Atorella vanhoeffeni collected in 1964 in the Indian Ocean.

(b) Colonial species: (1) Nausithoe punctata, the polyp of which was described by Allman (1874) as S. mirabilis. Collected in 1967 in the Adriatic Sea (Fig. 3). (2) Stephanoscyphus racemosus Koмar 1935, collected in 1969 at Seto, Japan (Figs 4, 5).

Simple methods are used. Mechanical stimulation is effected by a fine, blunt, acetone-cleaned glass rod. Flagellar currents are made evident by pipetting a carmine suspension near the surface in question.

\section{RESULTS}

\section{Anatomy and terminology}

Reference to Figure 1a, d, e will explain these features of the three polyp types. Further detail is found in ChapMAN \& WERNER (1972).

\section{Mechanical stimulation}

\section{Tentacles}

In still water the extended coronate polyp is motionless whereas there is slow tentacular writhing in Aurelia (Fig. 6) where, now and then, a tentacle can shorten and bend, usually in a "clasp-knife" fashion to the mouth (CHAPMAN 1965).

Most of the time the tentacles in all coronate polyps are filiform but a slight 

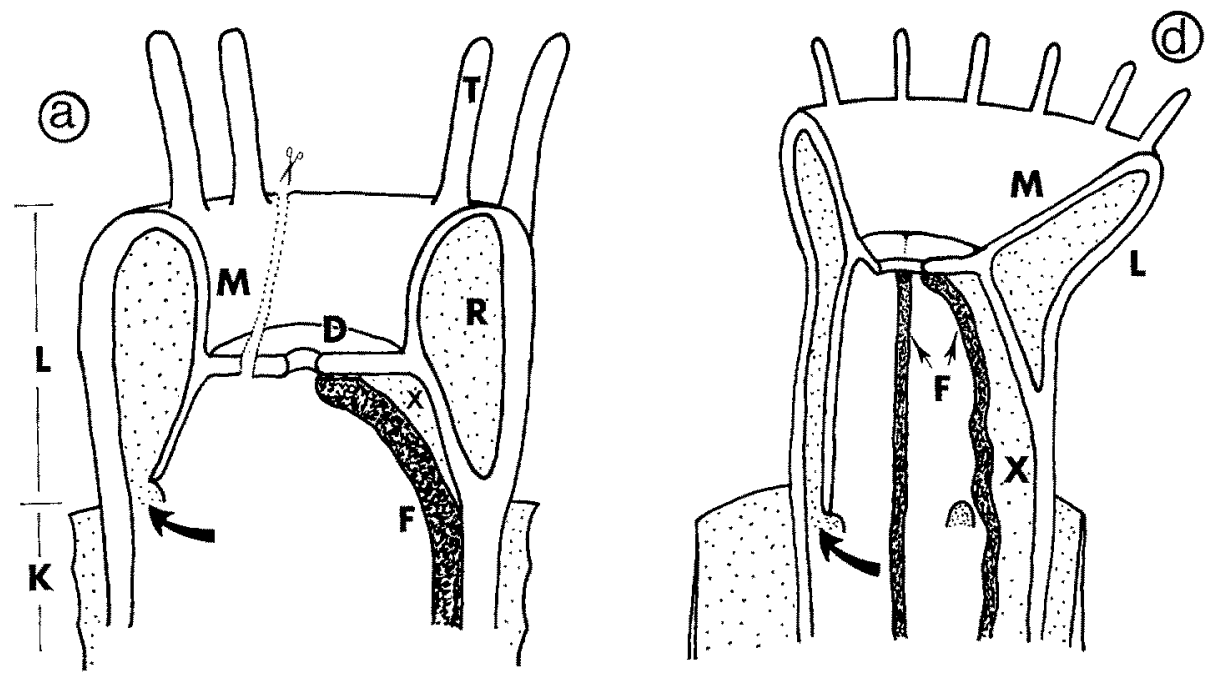

(b)
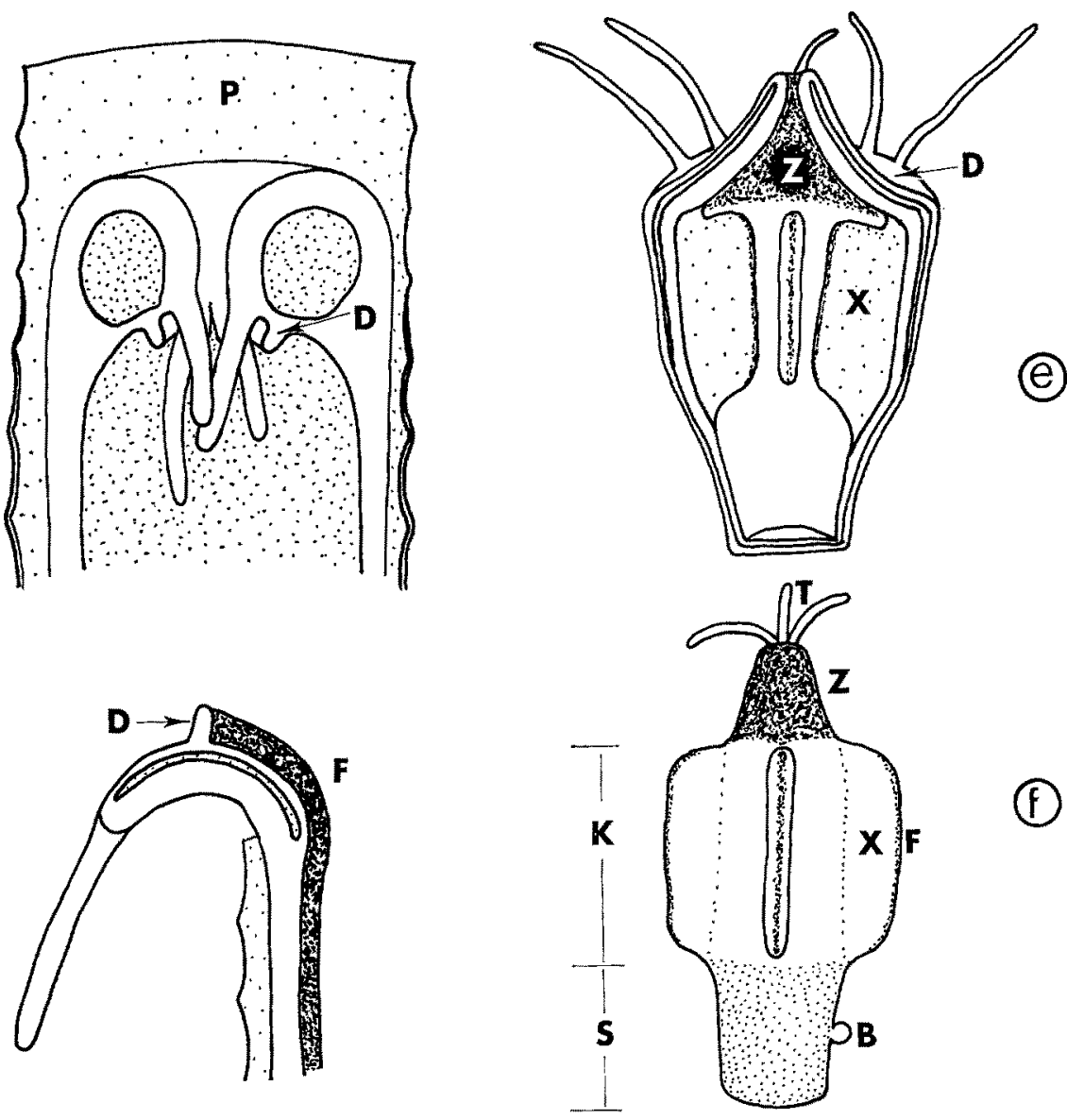
terminal clubbing can occur and this was noticed by Allman (1874). Sometimes the tentacles in Stephanoscyphus racemosus are kinky.

With regard to the usual coronate polyps, gentle stimulation with the rod on the distal region of the tentacle gives shortening distal to this point; gentle stimulation on a proximal region gives shortening proximal to this point as well as bending to the mouth, no doubt because of the thick oral disk muscle fibers which invade the lateral sides and adaxial face of the tentacles. When the tentacle turns out laterally again, the proximal part can still be in a shortened state. The distal part may shorten later as the tentacle is licked by the lips during the return from the coelenteron to the outside.

Strong tentacular stimulation can give shortening of the whole tentacle. Sometimes such stimulation will cause the crown to retract into the tube (Fig. 1 b) with a simultaneous shortening of all the tentacles. On occasions even gentle stimulation of a tentacle gives retraction of the crown. Apart from this reflex shortening, the tentacles seem neurologically isolated from one another because the stimulation does not spread to neighboring tentacles. Only once was an spontaneous shortening and bending into the mouth of two tentacles observed. During re-emergence of the crown, the tentacles are re-extended before the capitulum has started its ascent.

Stepbanoscyphus sp. 6 is not very efficient at impaling and ingesting Artemia. The tentacles when touched turn quickly into the mouth and although the mechanical stimulation is rather intense, the polyp quite adaptively does not retract as it would have done from a similar buffeting from the glass rod. The nauplii linger in the oral region of the coelenteron then slowly move aborally.

Strong prodding of a tentacle in Stephanoscyphus racemosus gives only a slight shortening; however, all the tentacles reflexly shorten when the crown retracts due to previous stimulation on other parts of the polyp. When a flap-like sector of the capitulum bends centrally (see below) the tentacles belonging to the sector shorten.

The behavioral similarities between the tentacles of the usual coronate polyps and Aurelia (Chapman 1965) are the lack of spread of stimulation to neighboring tentacles and the ability to give regional shortening along the tentacle; the differences are that strong tentacular stimulation in the usual coronates can give retraction of the polyp but not in Aurelia (Chapman 1965) and that during polyp retraction the tentacles of the usual coronates all shorten but in Aurelia they do not (CHAPMAN 1965).

Fig. 1: a Diagram of a usual coronate polyp (longitudinal cut-away view). Extended state. A per-radial view on the left shows a wide arrow at the per-radial opening of the ring sinus. The right shows an inter-radius with the flament $(F)$ ending at the mouth. $b$ Retracted state of a usual coronate polyp. The capitulum has been turned in centrally and retracted. The oral disk $(D)$ has also been retracted. $c$ Hyper-extended state during defecation of a usual coronate polyp. The crown is turned out laterally. The oral disk is retracted and the otal end of the flament is exposed on top. $d$ Stephanoscyphus racemosus (based on Komar 1935) in extended state. The wide arrow is at the per-radial opening of the sinus. The upper and lower sides of the capitulum correspond to the medial and lateral walls of the usual polyp's capitulum. $\varepsilon$ Scyphistoma of Aurelia aurita with one-half cut away. $f$ Scyphistoma of Aurelia aurita turned inside-out. A white ball is shown on the otherwise orange stalk endoderm. $B$, ball; $D$, oral disk; $F$, filament; $K$, calyx (the part of the body which gives rise to ephyrae); $L$, lateral wall of capitulum; $M$, medial wall of capitulum; $P$, periderm; $R$, ring sinus; $S$, stalk; $T$, tentacles; $X$, septum; $Z$, scyphopharynx 
Tentacles of all coronates are bent centrally by means of an invasion of special capitular muscle; in Aurelia bending is central even if the adjacent oral disk is excised (CHAPMAN 1965).

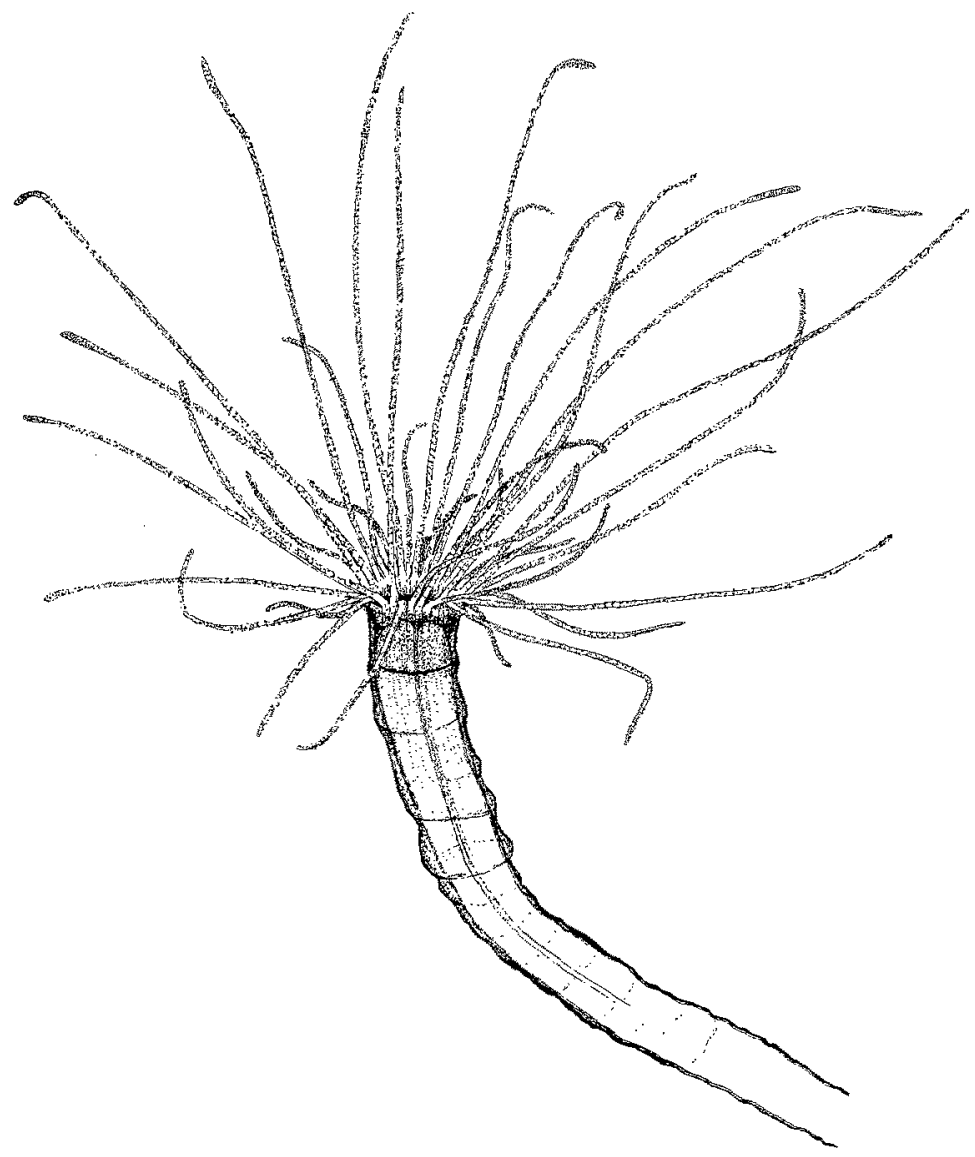

Fig. 2: Stephanoscypbus sp. 6, a drawing of the oral end of this solitary species. (From CrapMAN \& WERNER 1972, $20: 1$ )

\section{Oral disk}

With respect to the usual coronate polyps, the circular mouth can open spontaneously all the way round. The disk seems insensitive to touch midway between the mouth and its periphery because there is neither mouth opening, tentacle movement nor retraction of the polyp. Near the periphery, stimulation gave some localized tensing but not enough to force open the mouth on that side.

Touching the lip opens the mouth at the radius only. Even after stimulation has stopped, the lip shows some twitching here. 
Like Aurelia the mouth of Stephanoscypbus racemosus is cruciate. (The latter's lips are much smaller and there is no scyphopharynx.) Stimulation near the lip of S. racemosus causes the mouth to open on that radius.

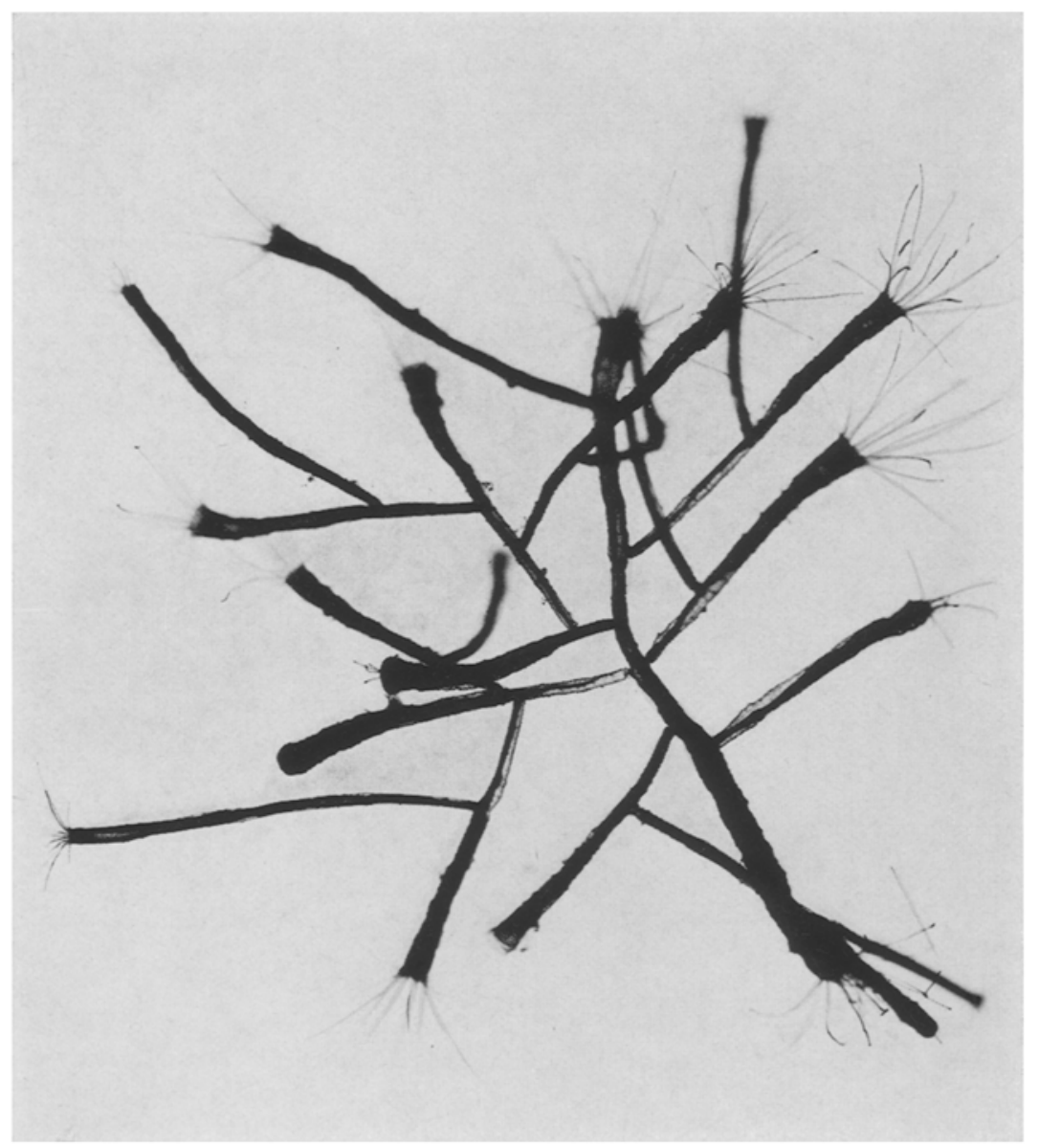

Fig. 3: Nausithoë punctata, a photograph of this colonial species, reared in the laboratory. (From Werner 1970;6:1)

The cruciate mouth of Aurelia has a lip sphincter and it is possible to get the lip to relax without causing the radial musculature of the disk to shorten (CHAPMAN 1965). Stronger stimulation at the lip causes a radial shortening of the oral disk but this action does not spread circumferentially. Apart from the lip the oral disk is rather insensitive but fairly strong stimulation causes retraction of the polyp. Since the usual coronate polyp has a circular mouth it is not possible to try the corresponding test. Aurelia's mouth can open spontaneously and writhe as well. 


\section{Capitulum}

Stephanoscyphus racemosus is like the usual coronate polyps if one thinks of the former condition being arrived at by a lateral spreading of a normal polyp's capitulum. In other words, the medial side of a usual polyp's capitulum corresponds to the upper side of the capitulum of $S$. racemosus; likewise, the lateral side in the usual polyp corresponds to the lower side in S. racemosus.

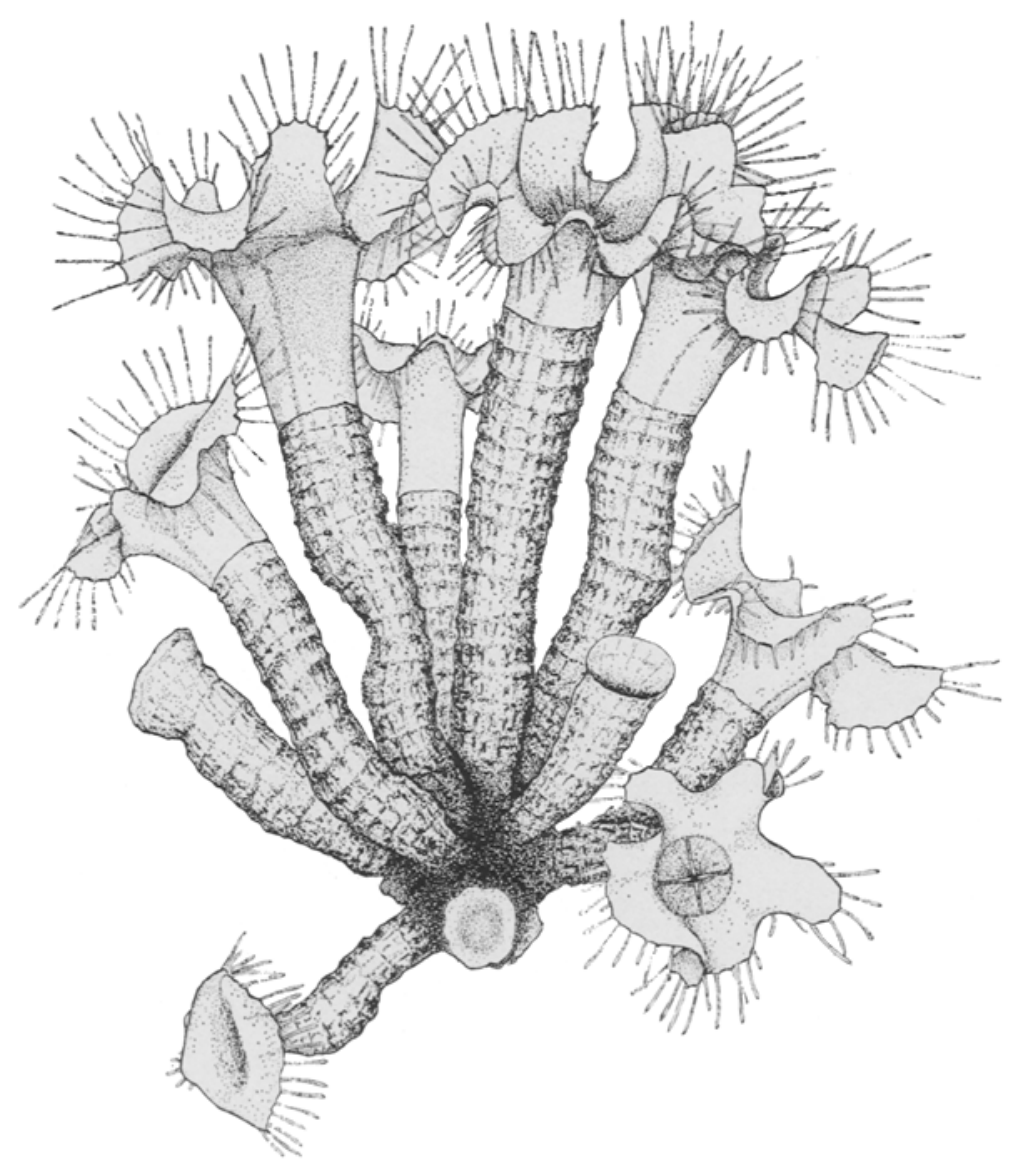

Fig. 4: Stephanoscyphus racemosus, a drawing of this atypical colonial species. (From Werner $1970 ; 14: 1)$

The lateral side of the capitulum of Nausitboë punctata is sensitive and causes the head to retract with reflex shortening of the tentacles. 
When the medial wall of the capitulum in Atorella vanboeffeni or Stephanoscyphus sp. 6 is touched, the wall bends towards the mouth which opens at this radius. and the tentacles near the point of stimulation shorten.

Turning to Stephanoscyphus racemosus, it is found that gentle stimulation of the upper side of the capitulum does not affect the mouth. Weak stimulation near the periphery causes the closest tentacles to bend in; moderate stimulation at the same

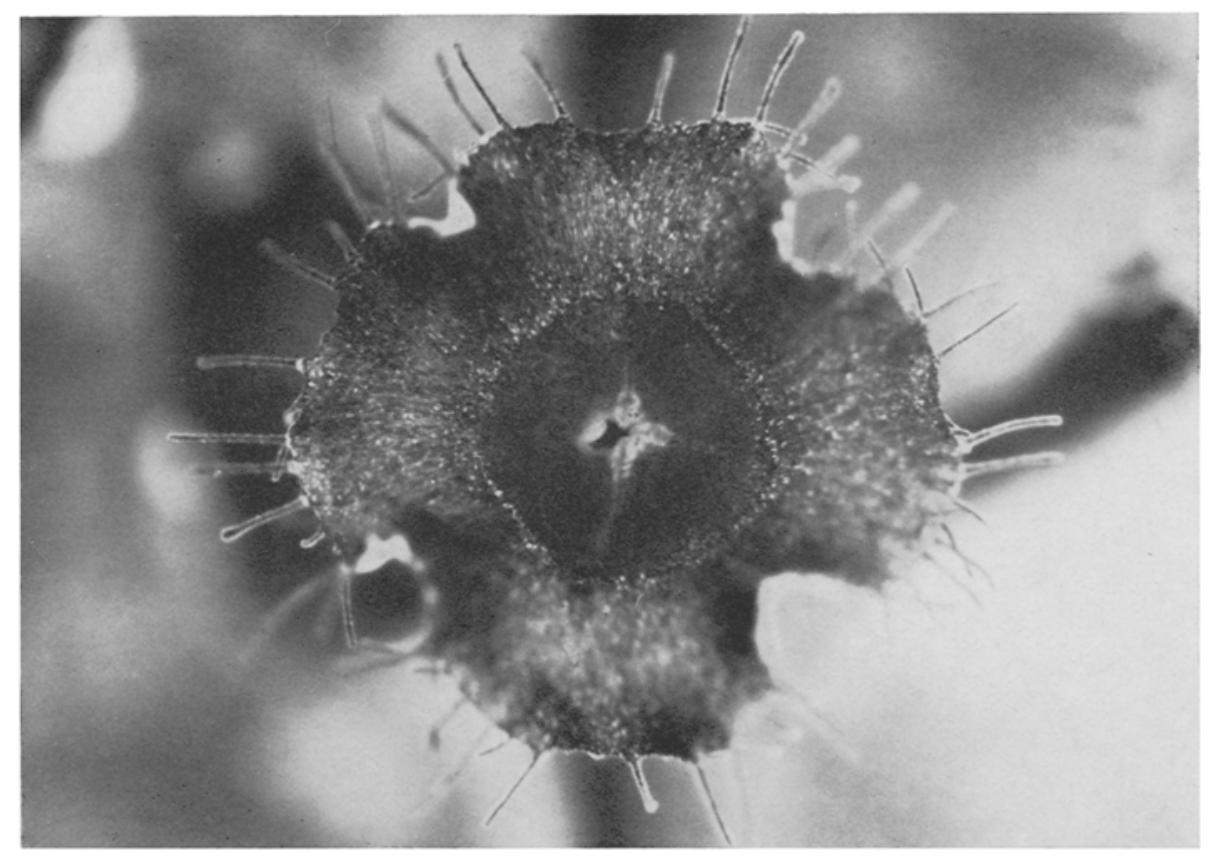

Fig. 5: Stephanoscyphus racemosus, a photograph of the oral end viewing the mouth. (From WERNER 1970; $22: 1$ )

place causes a flap of capitulum to bend in centrally and even after the flap returns, the tentacles on the flap stay shortened for a while; strong stimulation at the same place makes the polyp retract.

Stimulation of the lower surface of the capitulum brings about retraction of the polyp but other polyps in the colony are unaffected.

\section{Calyx and stalk}

In the usual coronate polyps the calyx and stalk are quite insensitive because the mid-point may be squeezed together without causing retraction of the crown. In one specimen the same result followed squeezing to one half the diameter at a point just 
$5 \mathrm{~mm}$ from the oral end. Dr. Werner, however, informs me that a strong squeeze at the mid-point of the body in all coronate polyps will cause retraction of the crown.

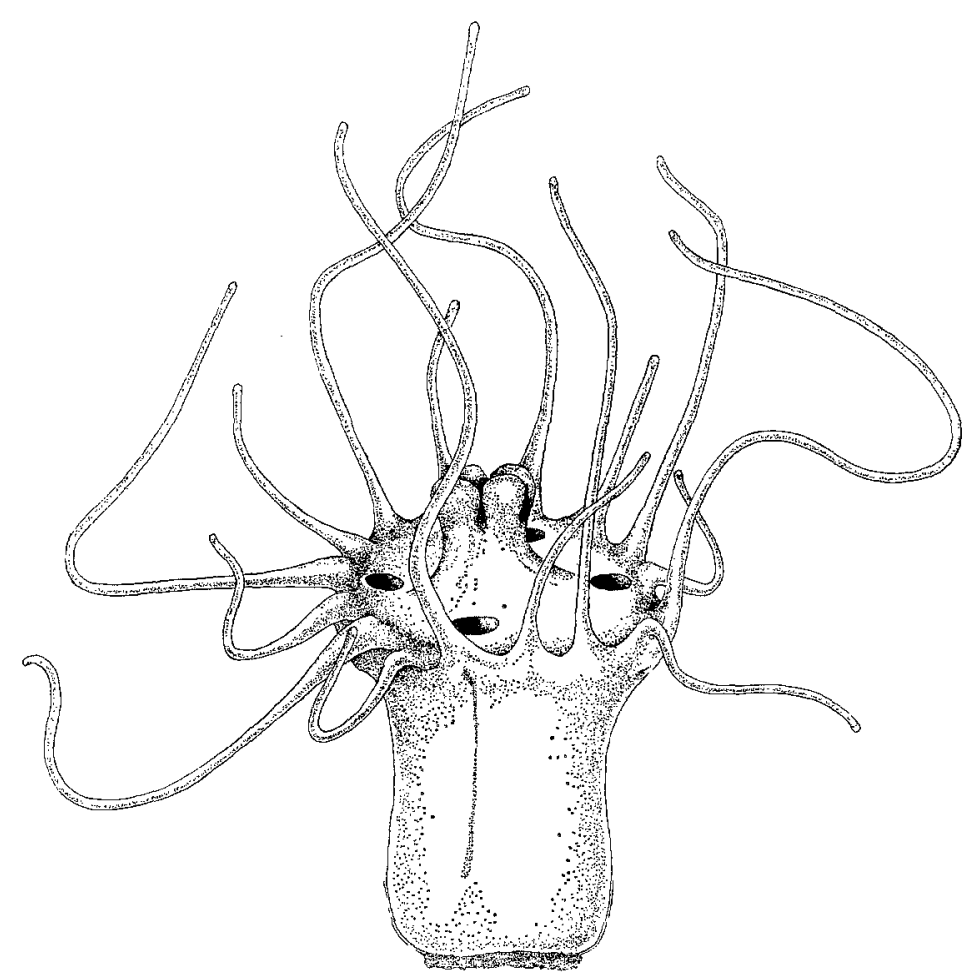

Fig. 6: Anrelia anrita, a drawing of the scyphistoma (WERNER, unpublished; $20: 1$ )

Stephanoscyphus racemosus, on the other hand, is sensitive to any touching of the calyx and stalk and retracts immediately.

Like the usual coronates, strong stimulation of the body wall of Aurelia fails to elicit retraction. When Aurelia has retracted due to stimulation elsewhere, the oral disk is still exposed and the polyp can feed. This is contrasted to the coronates in which the crown is turned in and retracted.

WERNER (1970) found that members of a colony of S. racemosus are connected by a basal scyphorhiza. When a region of the scyphorhiza of a large colony is touched the neighboring but not the remote crowns retract. Pressure on the scyphorhiza causes the distal ends of the retracted polyps to bulge. Nervous connections, internal pressure and mechanical agitation of retracting polyps are some hypotheses that need testing in order to account for the partial or mass involvement of the polyps. It seems more likely that there are no nervous connections between polyps. 
When a polyp of the typical colonial species, Nausitboë punctata, is carefully touched, the other polyps in the colony remain undisturbed (WERNER, personal communication). In fact in one of WERNER's regenerated polyps of $4 \mathrm{~mm}$ length with crowns at opposite ends, he was able to make one crown retract while the other was unaffected.

\section{Flagellar currents}

\section{Tentacles}

In the usual type (Stephanoscypbus sp. 1 and Atorella vanboeffeni) and S. racemosus, squash preparations show beating flagella but they are not co-ordinated to give a current (WERNER, personal communication).

Aurelia shows a definite current towards the tentacle tips (SoUthWARD 1955). Pérez (1920) made the same observation for Cyanea capillata.

\section{Oral disk}

Once again all coronate polyps have beating flagella but no well-defined currents. Aurelia shows a current on the oral disk in the direction of the mouth.

\section{Capitulum}

The lateral wall shows beating flagella but no currents when the crown is retracted (Atorella vanboeffeni). There is a very slow centrifugal current along the upper side of the capitulum in Stephanoscyphus racemosus and when a clump of carmine touches the base of a tentacle, a fold of this surface flips to the mouth. KOMAI (1935, p. 307) observed the current to take place in the opposite direction. In order to resolve this discrepancy, I requested Dr. WERNER to repeat this experiment. He is of the opinion there is no distinct current in any particular direction! He notes, however, a current is indirectly set up on this surface when the mouth opens to expose the strongly flagellated filaments which draw water into the coelenteron.

The undersurface of Stephanoscypbus racemosus, which is well exposed after retraction of the crown, shows a rather vague aboral current.

\section{Calyx and stalk}

The outside shows no beating flagella in coronates but Aurelia (SOUTHW ARD 1955) and Cyanea (PEREz 1920) show an orally directed current along the whole side of the polyp. Particles on reaching the origin of the tentacles would, on the basis of the previous observations, seem to have the choice of going on centrally along the oral disk or distally along a tentacle; however, they tend to go between the tentacles thence via the oral disk to the mouth. 


\section{Filament and defecation}

When the pigment is carefully pipetted into the coelenteron of the usual species, it can be seen that the carmine is transported aborally on the four filaments.

When a big squirt of carmine is administered, there is approximately a 4-minute delay before defecation. Defecation is a reflex involving a reversal of the slimy current on the filaments (and perhaps four weak per-radial currents) and a hyperextension of the crown, that is to say, the crown is spread out laterally and the oral disk contracted (Fig. 1c). This means the oral ends of the outwardly curved filaments become situated near the periphery so that material is dumped outside of the polyp. There is often a fast retraction after this phase of defecation so that perhaps defecation should include this aspect as well since it could presumably help clear out the coelenteron. In Atorella vanhoeffeni defecation is even possible after magnesium-sea water anaesthesia.

Dr. WERnER informs me that Stephanoscyphus racemosus shows flagellar reversal along the filaments during defecation.

In Aurelia, carmine is not rejected by defecation and none of the other features of defecation are noted; nevertheless, flagellar reversal can be demonstrated. If the scyphistoma is turned inside-out (Fig. 1f) by means of fine forceps and a blunt glass rod (CHAPMAN 1965), a rather crumpled specimen is produced but next day the specimen is well extended. The strongly flagellated scyphopharynx and filaments drive the carmine aborally in a brisk manner and even the stalk region contributes to the transport. When the polyp is prodded to produce shortening, flagellar reversal occurs and the whole everted lining of the coelenteron sends the carmine orally. The free edge of the septum is seen to have a minte pigment-laden groove.

Although pigment was not defecated, I am confident the remains of an Artemia nauplii meal would be seen to be discharged by this means.

An incidental observation worth recording in these everted specimens concerns the formation of white flagellated balls (Fig. 1f) of tissue pinched off from the orange stalk endoderm, so colored because of the diet of Artemia. These balls can glide about, and squash preparations show nematocysts.

\section{DISCUSSION}

\section{Behavior}

Although the anatomy of coronate and semaeostome polyps is rather different, a meaningful comparison may be drawn between the two and this has already been done in results.

Aurelia's neuromuscular system was divided by CHAPMAN (1965) on the basis of regional autonomy. This is to say, each division seems completely autonomous with respect to any observable neurological interaction. The polyp is nevertheless co-ordinated in a mechanical way during feeding as one division's action stimulates the next division into action by mechanical stimulation. Such a sequence depends therefore on the geometric relationship of the divisions to one another. 
Aurelia's autonomous divisions are: (1) The stolon-stalk-calyx division with ectodermal muscle fibers composed mainly of fine myofilaments. This system is rather insensitive in Aurelia and is lacking in coronate polyps. (2) The muscle cord division of Aurelia corresponds anatomically to the coronate muscle tubes. (3) The tentacular division. Although 2 and 3 are autonomous in Aurelia, there is some neurological interaction between the two in coronate polyps because strong stimulation of a tentacle gives a shortening of the four muscle tubes along with a shortening of all the tentacles and a turning in of the crown. The musculature of the coronate muscle tube is part of a larger continuous system also comprising the musculature of the medial wall of the capitulum and its extension into the tentacles (CHAPMAN \& WERNER 1972). (4). The radial system of the oral disk. (5) The circular or sphincteric system at the lip. The two polyp types are similar with respect to 4 and 5 .

Except for the lack of the number 1 division, the coronate polyp seems to be more complicated neurologically because the tube muscles and tentacles are co-ordinated neurologically unlike Aurelia. The reflex shortening of all the tentacles is certainly adaptive during retraction because of the cramped confines of the periderm tube.

CHAPMAN (1966) and especially WERNER $(1966,1967)$ have been recently promoting the view that the fossil conulariids were a type of scyphozoan polyp. The ability to shorten all the tentacles quickly at retraction would surely be helpful to a conulariid because of its four closing flaps with the danger of catching retreating tentacles.

\section{Flagellarcurrents}

Schulze (1877) quotes Eimer as saying the tentacles of the coronate polyp he observed were flagellated. Sometimes authors are not clear whether flagellation means they observed flagellar action or whether flagella stained in their microscopic preparations. The practical difference is important because not all flagellum-like structures are motile. Whatever EIMER's case, the present observations show no tentacular flagellar currents despite the fact they possess beating flagella.

Since flagellar reversal obtains, at least, for certain regions of these polyps, it is necessary to stipulate the nature of the marker particles because food particles might cause reversal. The physiological state (e.g. whether it is starved or defecating) is also relevant for related reasons. In this study the polyps were in a good nutritional state and the particular marker was the water-insoluble pigment, carmine.

PARKer \& Marks (1928) noted flagellar reversal in another cnidarian, the sea anemone Metridium. Inert material such as paper and coal dust were transported centrifugally on the oral disk but meat particles went towards the mouth. The change-over is not abrupt. The difference among KOMAI (1935, p. 307), WERnER (personal communication) and myself could probably be explained on the basis of the chemical nature of the particles. Unfortunately Komar failed to describe the nature of the particles he observed.

Perhaps the scyphistoma of Cyanea capillata can defecate because it can assume a posture very much like the coronate polyps. PÉREz $(1920$, his Figs 8,9$)$ shows the scyphistoma after a large meal with the mouth wide open, the tentacles turned basally 
and the oral end of the coelenteron partly everted. Extended observations of Aurelia after a meal of Artemia nauplii, would undoubtedly show that defecation is a normal occurrence in semaeostome polyps.

\section{SUMMARY}

1. On morphological and behavioral grounds as well as on the basis of flagellar currents, three scyphopolyp types can be recognized if one restricts oneself to the Orders Coronatae and Semaeostomeae. The coronates include the flower-like Ste phanoscyphus racemosus and the rest which are called the typical sort.

2. The three polyps could be compared, body region by region, with respect to their responses to touching with a glass rod. A previous study showed that the body regions of a semaeostome polyp were all neurologically isolated. The typical coronates, on the other hand, show more neurological interaction. When a tentacle is strongly stimulated, all the tentacles shorten and the polyp retracts.

3. The calyx-stalk region of the semaeostome polyp and the typical coronate polyps are rather insensitive to touch but the stalk of $S$. racemosus is sensitive.

4. The three polyps were compared, body region by region, with respect to flagellar currents as shown by the movement of carmine particles in sea water. Coronate polyps do not have tentacular flagellar currents whereas the semaeostome polyp has a current directed centrifugally.

5. Coronates can defecate. Sometime after a meal the head end hyperextends laterally and the flagellar currents along the filaments (four special bands in the coelenteron) reverse to beat towards the head thus clearing the debris from the coelenteron. This seems to be followed by a retraction of the polyp.

6. Aurelia was not observed to defecate but it likely does so; however, when it is turned inside-out the flagellar currents along its filaments can be made to reverse after prodding.

Acknowledgement. The author wishes to express his appreciation to Dr. B. Werner for making his laboratory in the Biologische Anstalt Helgoland available to me as well as for providing me with valued criticism of the manuscript and supplying additional observations.

\section{LITERATURE CITED}

Allman, G. J., 1874. On the structure and systematic position of Stephanoscyphus mirabilis, the type of a new order of Hydrozoa. Trans. Linn. Soc. Lond. 1, 61-66.

Chapman, D. M., 1965. Co-ordination in a scyphistoma. Am. Zool. 5, 455-464.

- 1966. Evolution of the scyphistoma. In: The Cnidaria and their evolution. Ed. by W. J. REes. Acad. Press, London, 51-75. (Symp. zool. Soc. London. Nr 16.)

- \& Werner, B., 1972. Structure of a solitary and a colonial species of Stephanoscyphus (Scyphozoa, Coronatae) with observations on periderm repair. Helgoländer wiss. Meeresunters. 23, 393-421.

Komai, T., 1935. On Stephanoscyphus and Nausithoë. Mem. Coll. Sci. Kyoto, Univ. (B), 10, 289-317. 
Parker, G. H. \& MARks, A. P., 1928. Ciliary reversal in the sea-anemone Metridium. J. exp. Zool. 52, 1-16.

Pérez, C., 1920. Un élevage de scyphistomes de Cyanea capillata. Bull. biol. Fr. Belg. 54, $168-178$.

Schulze, F. E., 1877. Spongicola fistularis, ein in Spongien wohnendes Hydrozoon. Arch. mikrosk. Anat. EntwMech. 13, 795-817.

SOUTHWARD, A. J., 1955. Observations on the ciliary currents of the jelly-fish Aurelid aurita L. J. mar. biol. Ass. U.K. 34, 201-216.

Werner, B., 1966. Stephanoscyphus (Scyphozoa, Coronatae) und seine direkte Abstammung von den fossilen Conulata. Helgoländer wiss. Meeresunters. 13, 317-347.

- 1967. Morphologie, Systematik und Lebensgeschichte von Stephanoscyphus (Scyphozoa Coronatae) sowie seine Bedeutung für die Evolution der Scyphozoa. Zool. Anz. (Suppl) 30, 297-319.

- 1970. Contribution to the evolution in the genus Stephanoscypbus (Scyphozoa Coronatae) and ecology and regeneration qualities of Stephanoscypbus racemosus Komar. Publ. Seto mar. biol. Lab. 18, 1-20.

Author's address: D. M. Chapman

Department of Anatomy

Dalhousie University

Halifax, N.S.

Canada 